\title{
The role of increasing riverbank vegetation density on flow dynamics across an asymmetrical channel
}

\author{
Manousos Valyrakis $^{1}$ (D) $\cdot$ Da Liu ${ }^{1} \cdot$ Umut Turker $^{2} \cdot$ Oral Yagci $^{3}$
}

Received: 27 October 2019 / Accepted: 8 April 2021 / Published online: 15 April 2021

(c) The Author(s) 2021

\begin{abstract}
Over the last two decades, the role of vegetation in the environmental and ecological restoration of surface water bodies has received much attention. In this context, the momentum exchange between the flow through the main channel and the riparian zone is a key mechanism. The primary goal of this study is to investigate the role of bank vegetation density on flow dynamics across the whole channel. This experimental study presents the major findings from a series of flow measurements across a channel having a sloping bank with vegetation at varying densities. The experiments are conducted under the same, uniform flow and fixed bed conditions, for a range of six linear and rectilinear arrangements of incremental streambank vegetation densities. A set of ten velocity profiles is obtained across the test cross-section of the channel, including the riverbank, for each vegetation density. These flow measurements are analyzed to derive roughness coefficients, which are related to the bulk flow velocities through the main channel and the riverbank and discuss the redistribution of flow velocities. An approximate doubling for the estimates of time-averaged boundary shear stress at the main channel, is observed for the case of no to dense vegetation, which enable further discussing implications for the stability of bed surface material. It is found that the vegetation arrangement, in addition to vegetation density, can have a strong impact in modifying the mean flow velocity at the main channel, for low riparian densities $(\varphi<0.6 \%)$.
\end{abstract}

Highlights - Flow dynamics are measured across the whole channel, including the vegetated riverbank.

- As stem density increases, mean flow velocity in the main channel increases while mean flow at the riverbank decreases.

- The arrangement of riparian vegetation can be as important as that of the density, in modifying the mean flow field of the main channel, for low riparian densities.

- Bed shear stresses at the main channel are estimated to increase with riverbank vegetation, reducing the stability of the stream's bed surface.

Keywords Vegetation hydrodynamics · Velocity measurements $\cdot$ Shear stresses $\cdot$ Riparian vegetation · Flow turbulence

Manousos Valyrakis

Manousos.Valyrakis@glasgow.ac.uk

Extended author information available on the last page of the article 


\section{Abbreviations}

$x \quad$ Longitudinal distance, $\mathrm{m}$

$y \quad$ Transverse distance, $\mathrm{m}$

$z \quad$ Vertical distance, $\mathrm{m}$

$W_{m} \quad$ Width of the main channel, $\mathrm{m}$

$W_{v} \quad$ Width of the vegetation section, $\mathrm{m}$

$\theta \quad$ Angle of sloping bank, degree

$\rho \quad$ Density of water, $\mathrm{kg} / \mathrm{m}^{3}$

$D_{50} \quad$ Median size of the sand bed layer,m

$D \quad$ Diameter of (rod shaped) individual vegetation element, $\mathrm{m}$

$s_{i} \quad$ Minimum spacing between individual vegetation elements, for configuration $i, \mathrm{~m}$

$r \quad$ Total number of vegetation elements along the riverbank

$\varphi \quad$ Solid volume fraction

$\lambda \quad$ Riverbank vegetation density, $\mathrm{m}^{-1}$

$h \quad$ Flow depth, $\mathrm{m}$

$Q \quad$ Flow discharge, $\mathrm{m}^{3} / \mathrm{s}$

$\frac{Q}{U} \quad$ Bulk flow velocity, $\mathrm{m} / \mathrm{s}$

$\bar{u} \quad$ Time average of point streamwise velocity measurements, $\mathrm{m} / \mathrm{s}$

$u^{\prime} \quad$ Fluctuating component of the instantaneous flow velocity $u, \mathrm{~m} / \mathrm{s}$

$\tau \quad$ Bed shear stress estimated with the logarithmic profile approximation, $\mathrm{Pa}$

$\tau_{*} \quad$ Shields parameter (normalized boundary shear stresses

\section{Introduction}

Riparian and aquatic vegetation can affect natural streams and waterways in many ways. It may alter flow conveyance, control riverbed and bank erosion and subsequently influence ecological indicators such as water and habitat quality due to contaminant re-suspension and transport. Re-vegetation of riverbanks is one of the common river restoration activities, which for the continental United States averaged about $1 \$$ billion annually [1]. A significant body of contemporary research studies in the wider research field of vegetation hydrodynamics has investigated the effects of individual element or patches of vegetation on flow velocity at various locations across the stream, ranging from the floodplain, riverbank and main channel [2-4]. Several studies have assessed the effect of vegetation density such as for emergent aquatic vegetation [5, 6], and for submerged vegetation [7]. Specifically, Nepf [5] used an experimental setup with rectilinear arrays of rods, illustrating the link between turbulence intensity within vegetation and hydrodynamic drag; Wilson et al. [7] conducted a laboratory study to compare the effects of aquatic vegetation on flow dynamics for the cases where rods with and without front canopy are used to simulate instream vegetation. However, in these experiments, even though the vegetation density has been locally changed (e.g., by adding canopy), the rectilinear pattern of vegetation array remained unaltered.

A series of experimental research studies (i.e. [8, 9]) showed that the time averaged streamwise velocity along a vegetated area of the stream would locally decrease, with vegetation density. However, the presence of riparian vegetation along stream banks or floodplains, may result in increased mean flow velocities as well as bed shear stresses in the main channel $[10,11]$. Many studies assessing the effect of vegetation density on the hydrodynamics of the main channel, generally show, that the relative turbulence intensity 
near the bed surface increases with the density of vegetation. For instance, Czarnomski et al. [12], used combinations of sparse and dense vegetation, with or without leaves, yielding four cases they compared to assess the effect on hydrodynamics past the vegetation elements. Kitsikoudis et al. [13], examined the flow through individual permeable instream vegetation elements, while Yagci et al. [14] focused on their effect on scouring the bed surface around them. These studies found that the complex interaction between vegetation, flow through it and the bed surface is dependent on the plant's anatomy. Yager and Schmeeckle [15] conducted a series of experiments focusing on the impact of instream vegetation on flow properties and sediment transport. They observed that eddies shed past the individual elements would be responsible for transport of bed material around them, similar to [16]. Nepf and Vivoni [17] and Liu et al. [18] also examined the effect of height of the vegetation patch on flow dynamics.

Recent studies show that the presence of vegetation generates an area of increased turbulence levels, which expands immediately downstream the element, separated from the mean flow by shearing layers $[8,12,17,19,20]$. In addition, the increase in turbulence intensity varies depending on the form and density of vegetation. For example, flexible riparian vegetation, such as grass and shrubs may generate more turbulence relative to rigid leafless vegetation $[4,11,12,14]$. A shear layer comprising of a range of length-scales of vortices and eddies may be observed to be generated by the riverbank vegetation at the interface of the vegetated zone with the main channel [12, 21, 22].

As may be seen from the above studies, until recently, research on both aquatic and riparian vegetation hydrodynamics has mainly focused on refining our fundamental understanding of the interaction of vegetation with flow dynamics. As these linked processes and feedback mechanisms are made clearer, several novel works begin expanding beyond such observations to investigate the impact on sediment transport. For example, in a relevant experimental study, Chen et al. [23] simulated emergent instream vegetation at increasing densities across the channel, to link flow dynamics, assessed with a series of velocity and turbulence intensity profiles, to the transport of sand. Schmeeckle [24] investigated the transport of sand around instream vegetation, with emphasis on the role of turbulence, the importance of which Sumer et al. [25] also outlined, for arrays of rigid cylindrical elements.

However, a thorough study of the body of literature in riparian hydrodynamics, reveals that a comprehensive investigation of the effects of the density of riverbank vegetation on the hydrodynamics across the full width of the river cross-section is lacking, thus far. The objective of this study is to contribute a set of results and findings based on experimental records of the flow velocity across a measurement grid spanning both the main channel as well as the vegetated riverbank, for increasing riverbank vegetation densities. Here, vegetation density is changed by gradually increasing the number of individual vegetation elements (represented by rigid rods without canopy), along linear and rectilinear arrays, to cover a range of representative densities found in natural streambanks. The experimental results are appropriately post-processed and presented in terms of mean streamwise velocity and mean bed shear stresses, to quantify the effects of different arrangements of increasing vegetation densities.

The focus of this research is to present new and more comprehensive analysis of the flow data obtained across the channel's cross-section and showcase that even though shear stress may be a reasonable parameter to use for unobstructed channel flows, it may have limited applicability, if any at all, in assessing riverbank stability. Specifically, an entirely new analysis is presented about the bed shear stresses across the main channel, for the range of examined stem densities of riverbank configurations, offering an in-depth 
extension of recent empirical observations [26], presented under a practical hydro-geomorphological framework. In addition, a generalized non-dimensional presentation on near bed flow velocity profiles and discussion on the effects on hydraulic roughness (which are of utility to practitioners), are demonstrated, supplementing the existing literature. Moreover, the current analysis offers an extended discussion beyond the initial observations on boundary shear stresses, allowing substantiating further any implications about the stability of bed surface at the main channel.

\section{Experimental methods}

\subsection{Description of the flume}

The experiment is conducted in a $14 \mathrm{~m}$ long by $1.8 \mathrm{~m}$ wide glass walled recirculating horizontal flume, with an asymmetrical cross-section, at the Water Engineering laboratory of the University of Glasgow (Fig. 1). This flume is an in-house modified version of an extended Armfield (C) flume with a bottom boundary made of concrete having a permanent longitudinal surface slope of $0.02 \%$. The streambank is modelled by a series of $0.8 \mathrm{~m}$ wide, inclined $\left(\theta=17^{\circ}\right.$, Fig. 2b) acrylic panels, running a streamwise length of $x=8 \mathrm{~m}$, starting from a short distance downstream of the inlet section of the flume. Flow into and out of the modified channel geometry with the riverbank cross-section is smoothly streamlined using airfoil shaped sections. Starting at about $2 \mathrm{~m}$ downstream the inlet, an approximately $1.6 \mathrm{~m}$ long and several centimeters thick layer of coarse gravel (of about $0.025 \mathrm{~m}$ median diameter), is placed as a filter layer to prevent loss of the bed material from the main channel, when the flume is drained. From the beginning of the inclined riverbank and along $8 \mathrm{~m}$, the $1 \mathrm{~m}$ wide main channel section $\left(W_{m}=1 \mathrm{~m}\right.$, Fig. $2 \mathrm{a}$ ) is layered with coarse nearly uniform and unisize sand of characteristic median size of about $0.002 \mathrm{~m}\left(1.2 \mathrm{~mm}<D_{50}<2.3 \mathrm{~mm}\right)$, up to a height of $0.075 \mathrm{~m}$ (Fig. 2b). At the inlet of the flume there is a smooth transition from the rectangular cross-section of the inlet to the cross-section with the inclined and vegetated bank (Fig. 1b). The vegetated region starts at a distance of $2.1 \mathrm{~m}$ from the flume inlet and extends for a length of $5 \mathrm{~m}$, while its width is $W_{v}=0.32 \mathrm{~m}$ (Fig. 2b). Near the flume outlet a layer of bricks of the same thickness as the sandy bed, extend a false bed to ensure negligible loss of sediment during the experimental runs.

\subsection{Description of the test section and flow conditions}

The test area is located $0.5 \mathrm{~m}$ from the downstream end of the vegetated region (Fig. 1c,d). The location for the cross-section is chosen to be sufficiently distant from the inlet of the flume, so as to ensure that the flow field has been fully developed, as modified by the vegetated riverbank at different densities [27]. Specifically, the mean flow velocity profiles at the centerline of the main channel, at longitudinal distances of the test section and one meter downstream are found to be almost identical (less than a max 3\% difference of the corresponding local mean flow velocities, across the flow depth). This is ensured by means of checking the averaged velocity profiles for subsequent cross-sections and assessing any variability between them. Near uniform flow conditions are established (flow depth measurements had an indiscernible difference of less than $5 \%, 1 \mathrm{~m}$ upstream and downstream the cross-section of the test area) by appropriately adjusting the tailgate's height, until no variability of the flow depth along the flow direction is discernable. The measured flow 
Fig. 1 Upstream view of the flume from the inlet, showing the simulated riverbank (inclined acrylic panel), the channel bank simulated vegetation (vertically placed rods supported by the panels and frame attached to the flume wall) and the main channel comprising of a coarse sand bed surface layer
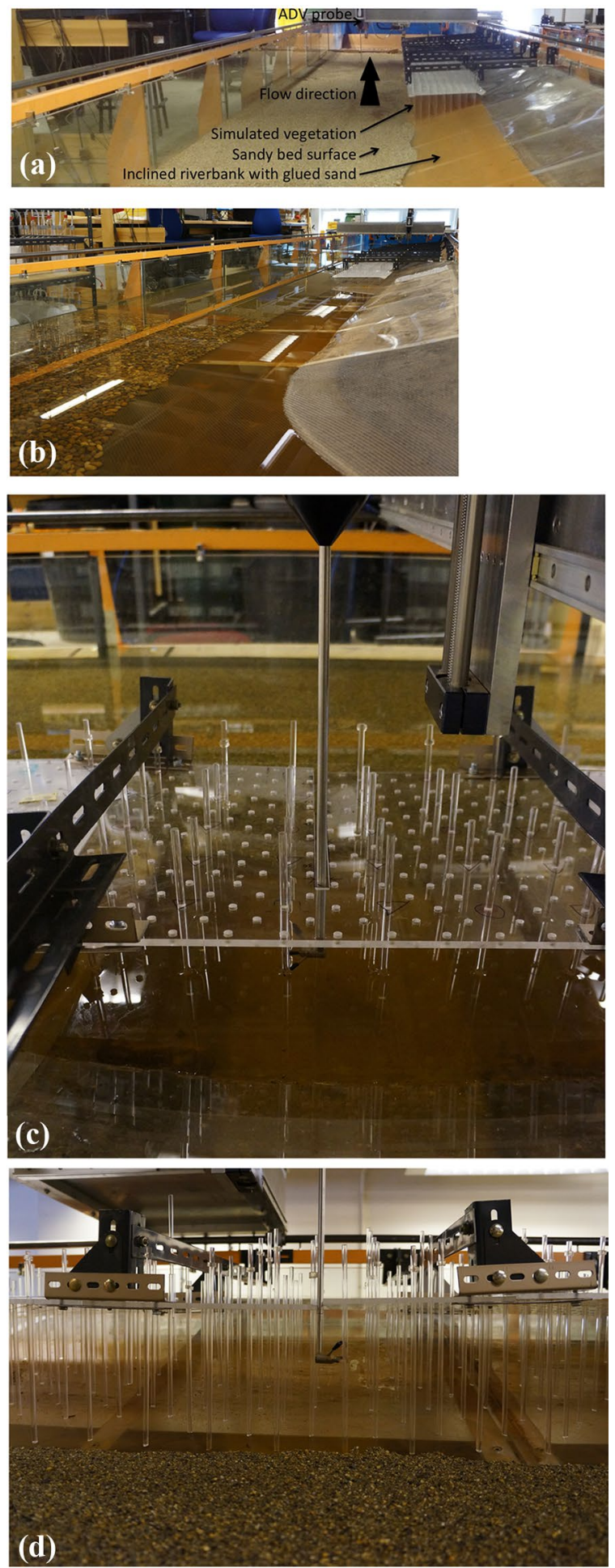
(a)

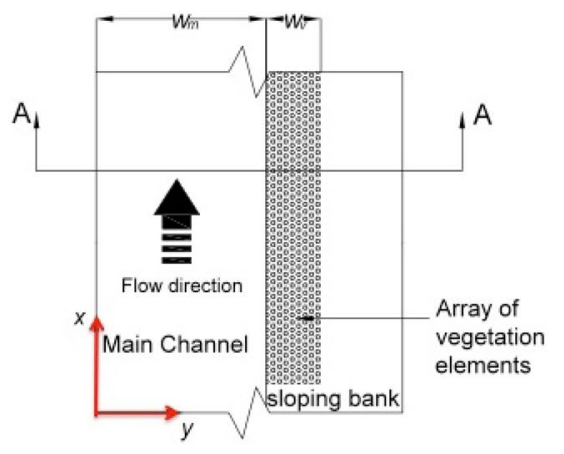

(b)

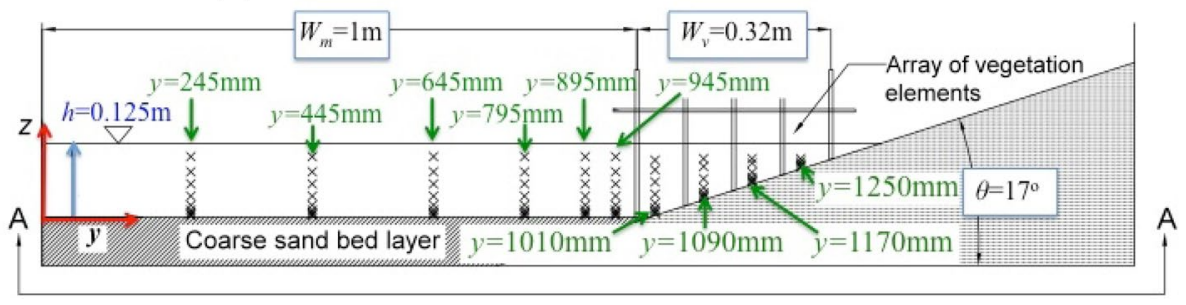

Fig. 2 a Plan view of the channel setup with a vegetated riverbank, simulated by an array of vegetation elements (rods) placed at a variable density along the sloping riverbank. A reference coordinate system is also shown, b Cross-sectional layout of the channel (A-A) showing the of measurement grid locations ( $\times$ symbols, more densely spaced near the solid boundary). The width of the main channel and riverbank are denoted with $W_{m}(=1 \mathrm{~m})$ and $W_{v}(=0.32 \mathrm{~m})$ respectively

depth values for each riverbank vegetation density did not change more than about $\pm 2 \%$ of the flow depth, nor in any consistent way, which is acceptable considering the inherent uncertainties in the experimental observations. Once the pumps recirculating water in the flume are set to the target flow conditions, the flow hydraulics are left fixed at that rate, to stabilize, for about $2 \mathrm{~h}$, allowing to reach steady flow conditions. Thus, the flow at the test area, located $4.5 \mathrm{~m}$ from the start of the vegetated section, is steady and uniform, with a flow depth of about $0.125 \mathrm{~m}$ and a cross-sectional mean flow velocity of about $0.047 \mathrm{~m} / \mathrm{s}$. The mean flow velocity is estimated via two independent techniques returning matching results. A first range of estimates is derived by means of spatially averaging the measured flow velocities along the measurement grid at the channel's cross-section, for each experiment. The second method of estimation employs point measurements of the flow velocity at the centerline of the water recirculating pipes with electromagnetic current flow meters (ECMs). Positioning these flow meters perpendicular to the wall of the pipes, and inputting pipe characteristics (including pipe's external diameter, wall thickness, wall material and lining), allows obtaining the velocity at the centerline of the pipe they are attached to. Assuming a turbulent flow profile through the pipe and measuring the maximum velocity (at the pipe's centerline) allows for obtaining an estimate of the flow through each recirculation pipe and the total discharge through the flume. The flow rate is controlled via two pump inverters remaining fixed at the target flow rate for all runs, as also validated by the indications of the electromagnetic flow meters. The flow conditions are chosen appropriately, so that the bed surface (reference level, $z=0$, Fig. 2b) remains stable during the 
experiments, as measured with the aid of two digital height measurement gauges with submillimeter resolution $(0.01 \mathrm{~mm})$, mounted on the flume's transverse platform to ensure the gravel bed is approximately leveled. Using these measurement gauges and rulers fixed on the vertical sidewall of the flume, at different locations along the $\mathrm{x}$ direction, the water depth was measured.

\subsection{Experimental design and range of vegetation arrangements}

A large number of $D=0.006 \mathrm{~m}$ diameter acrylic dowels (cylindrical rods) of varying and sufficient height are used to model stiff, emergent riverbank vegetation. The ends of the rods are appropriately cut (at the same angle $\theta$ as the sloping bank) so as to allow a perfect fit when placed appropriately along the inclined bank surface. The rods are spaced apart at a distance $s_{i}$ from each other (Fig. 3), depending on the desirable layout pattern for each vegetation density, and are vertically held into position by a series of support panels. These panels are suspended at a sufficient distance above the water surface and along the bank and held into position supported with a metal framework bolted to the sidewall of the flume, offering a versatile configuration (Figs. 1a-d and 2b). The panels have a repeating

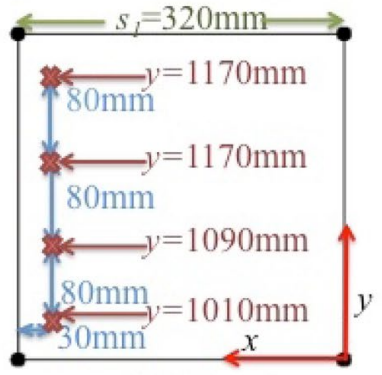

conf. 1 (linear) $\varphi=0.06 \%, \lambda=0.06 \mathrm{~m}^{-1}$

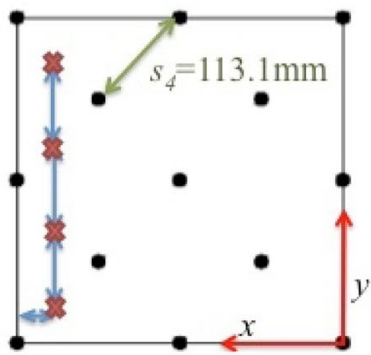

conf. 4 (rectilinear) $\varphi=0.28 \%, \lambda=0.47 \mathrm{~m}^{-1}$

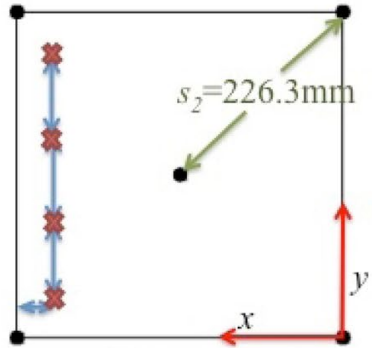

conf. 2 (rectilinear) $\varphi=0.08 \%, \lambda=0.12 \mathrm{~m}^{-1}$

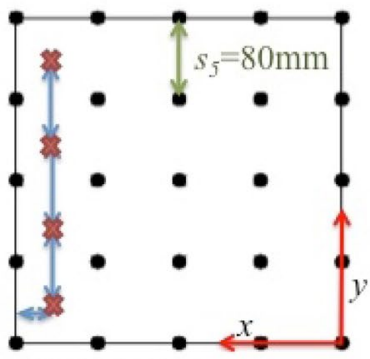

conf. 5 (linear) $\varphi=0.55 \%, \lambda=0.94 \mathrm{~m}^{-1}$

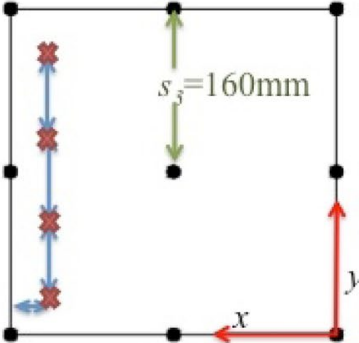

conf. 3 (linear) $\varphi=0.17 \%, \lambda=0.23 \mathrm{~m}^{-1}$

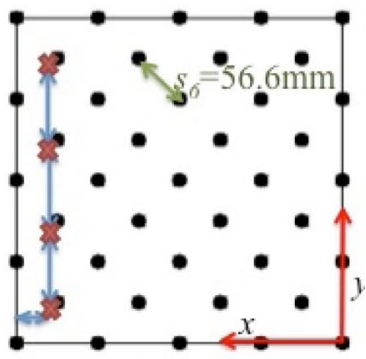

conf. 6 (rectilinear) $\varphi=0.99 \%, \lambda=1.88 \mathrm{~m}^{-1}$

Fig. 3 Illustration of the six configurations of simulated riverbank vegetation (shown with black circles) used in the experiments for various vegetation densities, $\lambda$, and $\%$ of solid volume fraction, $\varphi$. The relative position of the flow measurements within the vegetated section are shown with a thick red " $\mathrm{x}$ " symbol and their spacing relative to the sparsest configuration is shown (top left subplot). The between elements minimum spacing, $s$, for each configuration (see also Table 1), is shown, for the linear and rectilinear configurations. Flow direction is along the $x$-axis. The flow velocimetry measurement grid is set in a way so as to minimize interference from individual vegetation elements for all of the vegetation densities tried herein 
pattern of drilled holes, replicating the above layout, through which the acrylic rods can be conveniently placed at certain fixed locations, yielding the linear configurations $1,3,5$ or the rectilinear (staggered) configurations 2, 4, 6 (Fig. 3). Following these arrangements, the rigid rods are put in place in an incremental manner, resulting in between elements minimum spacing $\left(s_{j}\right)$, from $s_{1}=0.320 \mathrm{~m}, s_{2}=0.226 \mathrm{~m}, s_{3}=0.160 \mathrm{~m}, s_{4}=0.113 \mathrm{~m}, s_{5}=0.080 \mathrm{~m}$ and $s_{6}=0.057 \mathrm{~m}$, so that increased simulated riverbank densities can be achieved (Fig. 3 and Table 1).

Similar to past experimental studies [5, 7], focusing on emergent rigid vegetation simulated with cylindrical elements of constant diameter $D$, a definition for the vegetation density $(\lambda)$, may be offered based on the momentum absorbing frontal area of the individual elements per canopy volume, as the ratio of the projected area to the total volume:

$$
\lambda=D / s_{i}^{2}
$$

where $s_{i}$ denoted the spacing between adjacent individual vegetation elements (Fig. 3). Six configurations (linear and rectilinear) of vegetation density are examined, with the vegetation density ranging from $\lambda=0.06 \mathrm{~m}^{-1}$, for the linear arrangement of configuration 1 , to $\lambda=1.88^{-1}$, for the rectilinear arrangement of configuration 6 (Table 1 ). This range of densities is representative of many examples of tall aquatic and riparian emergent vegetation found in nature and has been employed in many past studies (i.e., see [5, 11, 18] among others). The vegetation density $\lambda$, may not suffice alone for describing the effect of element's diameter or arrangement or number of elements. Thus, in addition to the vegetation density $\lambda$, the solid volume fraction $\varphi\left(\varphi=m \pi D^{2} /\left(4 L W_{v}\right), m\right.$ denotes the total number of rods along the riverbank section) is also calculated. This is representative of the areal coverage of the vegetation elements, as the portion of unit area covered by vegetation elements and is reported in Table 1 for the range of vegetation densities assessed herein.

The range of vegetation densities formed by the individual elements $(D=0.006 \mathrm{~m})$ examined here range from very sparse $\left(\lambda=0.06 \mathrm{~m}^{-1}, \varphi=0.06 \%\right)$ to dense arrangements $\left(\lambda=1.88 \mathrm{~m}^{-1}, \varphi=0.99 \%\right)$, resembling vegetation found in natural marsh (e.g., spartina species), meadows or mangrove systems (such as Avicennia and Rhizophora species) [28-32]. There exists a plethora of types of riparian vegetation that are suitably modelled by the range of vegetation densities simulated herein. The defining characteristic for translating the results from this research to the distinct types of vegetation as found in nature, is the individual vegetation element trunk diameter, on the basis of which the channel, bed surface and flow parameters scale, by applying geometric similarity. Beyond this scaling parameter, one may be successful in generalising the results presented herein, depending

Table 1 Representation of the relevant geometrical aspects for each configuration (rod arrangement type; individual minimum element spacing, $s_{i}$; vegetation density, $\lambda$; and $\%$ of solid volume fraction, $\varphi$ )

\begin{tabular}{llllll}
\hline $\begin{array}{l}\text { Con- } \\
\text { figura- } \\
\text { tion \# }\end{array}$ & Rod arrangement & $\begin{array}{l}\text { Number } \\
\text { of rods } \\
(r)\end{array}$ & $s_{i}[\mathrm{~cm}]$ & $\lambda\left[\mathrm{m}^{-1}\right]$ & $\varphi[\%]$ \\
\hline 1 & Linear & 30 & 32 & 0.06 & 0.06 \\
2 & Rectilinear & 45 & $32 \sqrt{2 / 2}$ & 0.12 & 0.08 \\
3 & Linear & 90 & 16 & 0.23 & 0.17 \\
4 & Rectilinear & 150 & $16 \sqrt{2 / 2}$ & 0.47 & 0.28 \\
5 & Linear & 300 & 8 & 0.94 & 0.55 \\
6 & Rectilinear & 540 & $8 \sqrt{2 / 2}$ & 1.88 & 0.99 \\
\hline
\end{tabular}


on the degree to which a number of assumptions may apply. Such assumptions can be that the vegetation is leafless or that its submerged portion does not have submerged canopy or that any of its canopy does not significantly modify the flow field. The setup presented herein may be sufficiently descriptive of the hydrodynamics of those natural systems or appropriately scaled systems (using geometric and dynamic similarity), under the assumption of low degree of deformation (eg of the individual vegetation elements trunk), which generally holds true, for many of these cases. Thus, this study focuses on using rigid cylindrical dowels (e.g., similar to $[5,11,18]$ ), to simulate the effect of vegetation density on the flow field, which may find application to a number of practical hydraulic engineering and ecological restoration cases, where the little or no canopy is seen by the flow and the vegetation remains unbent by the normal stream flow.

\subsection{Experimental protocol}

A side looking, acoustic Doppler velocimeter (ADV) from Nortek® is used to record sufficiently long time series of the three components of the instantaneous flow velocity at various locations along a measurement grid (denoted along the plane $\mathrm{y}-\mathrm{z}$, with the symbols "x", in Fig. 2b), at the test cross-section (located about $8 \mathrm{~m}$ downstream from the flume's inlet - also see Fig. 1c,d). As shown in Fig. 2a the measurement grid is denser at the near bed. For the hydrodynamic measurements, the velocimeter probe is mounted on a movable platform, facing upstream, so that it could transverse to any desirable location along the channel's cross-section. A cut across one of the panels at the test section, allowed for traversing the ADV, at specific locations within the riverbank, appropriately chosen so as to enable obtaining flow measurements unobstructed from the simulated vegetation elements upstream. The orientation relative to the flow and careful selection of the ADV probe sampling locations within the riverbank, ensure reliable and non-intrusive flow diagnostic measurements.

The measurement grid used to assess flow dynamics comprised of three velocity profiles at the main channel (from $y=0.225 \mathrm{~m}$ to $0.645 \mathrm{~m}$ ) and three profiles (from $y=0.795 \mathrm{~m}$ to $0.945 \mathrm{~m}$ ) at the interface between the main channel and sloping bank, capturing the development of the shear velocity layer (Fig. 2a). The exact lateral ADV placement locations are shown in Fig. 2b. Each profile consisted of 9 measurement points, with elevations ranging from $\mathrm{z}=0.009 \mathrm{~m}$ to $0.100 \mathrm{~m}$ above the bed surface $(\mathrm{z}=0 \mathrm{~m})$. Another four profiles (each having 6 to 9 measurement locations, totalling up to 30) recorded the flow dynamics within the vegetated riverbank (Fig. 2a). For these profiles, the location of measurement points is varied in a consistent manner, starting from $z=0.009 \mathrm{~m}$ from the inclined bank surface, and getting as close to the water surface as possible, while having regularly spaced intervals, beyond a short distance from the solid boundary. Recordings, where taken at a sampling frequency of $25 \mathrm{~Hz}$, over a period of more than four minutes each, resulting in more than 6000 ADV point velocity measurements per location, which is sufficient for reporting averaged flow dynamics (max variation of local mean flow velocity measurements are less than $6 \%$, as calculated for temporal means of 1.5-4 min). Given a sufficient density of measurements near the riverbed and streambank, the near bed shear stresses can be estimated in addition to mean flow velocity profiles. 


\section{Results}

\subsection{Mean streamwise velocity across the channel}

The raw velocity data obtained from the ADV for each vegetation configuration are checked for sufficient signal quality and are post-processed by means of applying appropriate filtering methods as described in Goring and Nikora [33] to remove any outliers. The measured instantaneous streamwise velocity signal $u$ comprised of the time-averaged mean velocity $\bar{u}$ and fluctuating component $u$ ', according to Reynolds' decomposition $(u=\bar{u}+u \prime)$. The time-averaged mean velocity component is computed from the collected time series at each measurement location, according to:

$$
u=\frac{1}{n} \sum_{i=1}^{n} u_{i}
$$

where $n$ is the number of measurements during the sampling run. Such mean values of the streamwise velocity are calculated at each point across the measurement grid, throughout the channel's cross-section, including the riverbank (Fig. 2b). Using the bulk flow velocity (estimated via the calculation of total flow discharge measured with the electromagnetic current meters or independently via spatial averaging of the acquired velocimetry data across the flume's cross-section), the point velocity averages can be normalised, to allow generalisation of the results to different flow discharges. The resulting normalised time averaged streamwise velocity profiles for all vegetation densities at each of the various locations across the main channel, including the main channel region ( $y=0.245 \mathrm{~m}$ to $0.645)$ and the region at the interface of the main channel with the vegetated riverbank $(y=0.795 \mathrm{~m}$ to $0.945 \mathrm{~m})$, are shown in Fig. 4, while the profiles corresponding to the vegetated riverbank region are shown in Fig. 5.

\subsection{Normalised representation of the mean streamwise velocity across the main channel}

It can be clearly observed that the normalised streamwise velocity profiles at various locations across the riverbank may be reduced with increasing vegetation density, as denoted from an increasing solid volume fraction of $\varphi=0.06-0.99 \%$ or vegetation density $\lambda=0.06$ to $1.88 \mathrm{~m}^{-1}$ (see Fig. $5 \mathrm{a}-\mathrm{d}$ ). The increase of vegetation density has the opposite effect for the mean flow velocities at the main channel (Fig. 4a-f). Specifically, it is worth focusing the discussion of these results at the mid-depth of the flow $(z / h=0.5)$ to quantify those changes. For example, for the second configuration $(\varphi=0.08 \%$ or $\lambda=0.12 \mathrm{~m}^{-1}$ ) the flow velocity at the mid-depth of the main channel, when compared to the mid-depth velocity at $y=0.245 \mathrm{~m}$, can change from less than $10 \%$ at the centerline $(y=0.445 \mathrm{~m}$, Fig. $4 \mathrm{~b})$ to $-21 \%$ at the interface with the vegetated bank $(y=0.945 \mathrm{~m}$, Fig. 4f). However, for the denser configurations (for example configuration 6 with $\varphi=0.99 \%$ or $\lambda=1.88 \mathrm{~m}^{-1}$ ), the relative change for the same locations is $+5 \%$ (Fig. $4 \mathrm{~b}$ ) and $-40 \%$ (Fig. 4f) respectively, showcasing the pronounced effect of flow blockage at the riverbank due to dense vegetation. This "blockage" effect is accompanied with an increase of the flow through the main channel. For example, the mid-depth mean 
(a)
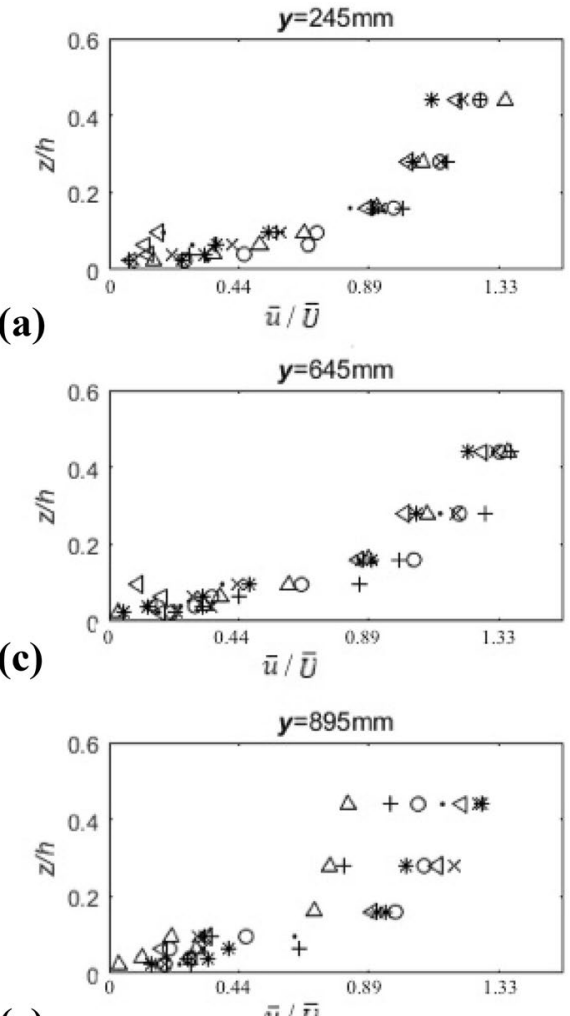

(e)
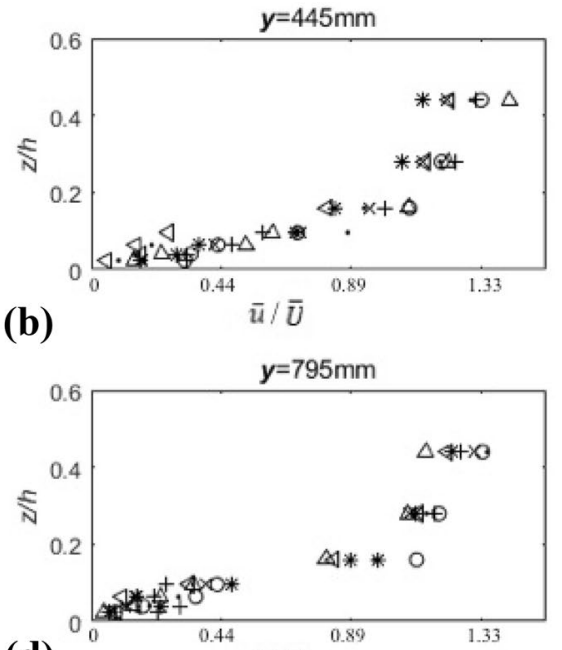

(d)

$\bar{u} / \bar{U}$

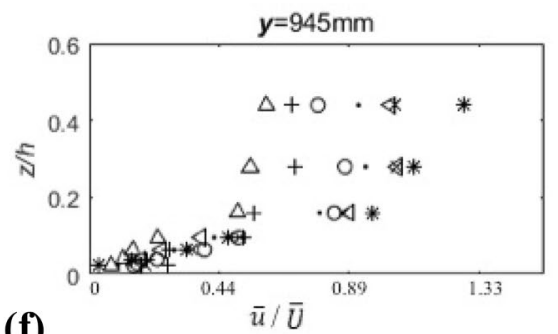

(f)

$\begin{array}{ll}\triangle \lambda=0.06 \mathrm{~m}^{-1} & \times \lambda=0.12 \mathrm{~m}^{-1} \\ +\lambda=0.94 \mathrm{~m}^{-1} & \Delta \lambda \lambda=1.88 \mathrm{~m}^{-1}\end{array}$

Fig. 4 Plots of normalized mean streamwise velocity $(\bar{u} / \bar{U})$ profiles for characteristic transverse locations at the main channel $(y=0.245 \mathrm{~m}$ to $0.945 \mathrm{~m})$, for different arrangements of increasing vegetation densities (as denoted from increasing solid volume fractions of $\varphi=0.06$ to $0.99 \%$ or vegetation densities $\lambda=0.06$ to $1.88 \mathrm{~m}^{-1}$ )

normalised streamwise flow velocity at the centerline of the main channel $(y=0.445 \mathrm{~m}$, Fig. 4b), increases from 1.2 for configuration 2 (for $\varphi=0.12 \%$ or $\lambda=0.12 \mathrm{~m}^{-1}$ ) to 1.42 for configuration $6\left(\varphi=0.99 \%\right.$ or $\left.\lambda=1.88 \mathrm{~m}^{-1}\right)$, recording an increase of about $18 \%$ For the same location (Fig. 4b), the velocity increases from about $26 \%$ to only $9 \%$ for the cases of $\varphi=0$ (no vegetation) and $\varphi=0.55 \%$ or $\lambda=0.94 \mathrm{~m}^{-1}$ (configuration 5) when compared to $\varphi=0.99 \%$ (configuration 6), respectively. A decreasing trend for the mid-depth streamwise velocities is instead observed for the region near the vegetated bank (e.g., $y=0.895 \mathrm{~m}$, Fig. $4 \mathrm{e}$ and $\mathrm{y}=945 \mathrm{~mm}$, Fig. 4f). In particular, the mid-depth streamwise velocity can be reduced from 16 to $35 \%$ for configurations $5(\varphi=0.55 \%$ or $\left.\lambda=0.94 \mathrm{~m}^{-1}\right)$ and $2\left(\varphi=0.08 \%\right.$ or $\left.\lambda=0.12 \mathrm{~m}^{-1}\right)$, when compared to configuration 6 $\left(\varphi=0.99 \%\right.$ or $\left.\lambda=1.88 \mathrm{~m}^{-1}\right)$. 
(a)

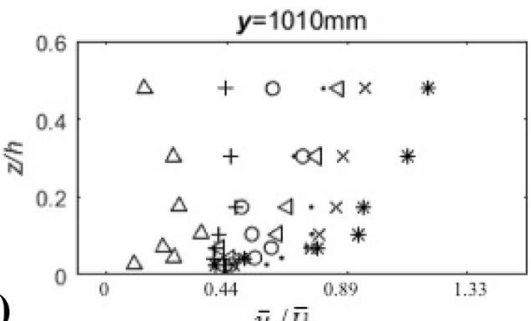

(c)

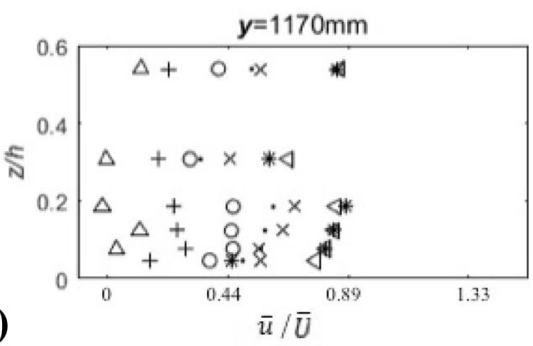

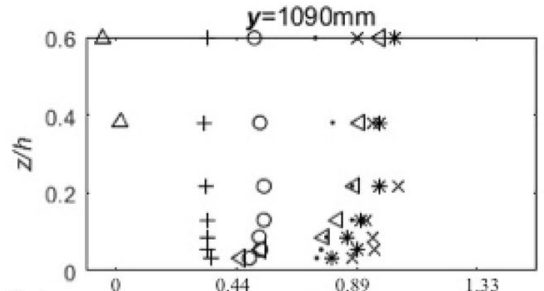

(b)

$\bar{u} / \bar{U}$

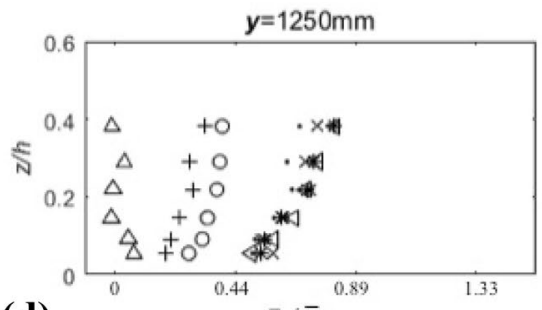

(d)

\begin{tabular}{|llll|}
\hline * No vegetation & $\triangleleft \lambda=0.06 \mathrm{~m}^{-1}$ & $\times \lambda=0.12 \mathrm{~m}^{-1}$ & $\cdot \lambda=0.23 \mathrm{~m}^{-1}$ \\
$\circ \lambda=0.47 \mathrm{~m}^{-1}$ & $+\lambda=0.94 \mathrm{~m}^{-1}$ & $\Delta \lambda=1.88 \mathrm{~m}^{-1}$ & \\
\hline
\end{tabular}

Fig. 5 Plots of mean normalized streamwise velocity $(\bar{u} / \bar{U})$ profiles for characteristic transverse locations at the slopping bank ( $y=1.010 \mathrm{~m}$ to $1.250 \mathrm{~m}$ ) for different arrangements of increasing vegetation densities (as denoted from increasing solid volume fractions of $\varphi=0.06 \%$ to $0.99 \%$ or vegetation densities $\lambda=0.06$ to $\left.1.88 \mathrm{~m}^{-1}\right)$

\subsection{Normalised representation of the mean streamwise velocity across the vegetated riverbank}

For all assessed densities, the velocities at specific flow depths measured at the region of sloping bank are relatively lower to those at the main channel, as assessed by qualitatively comparing the normalized streamwise velocity profiles shown at Fig. 4 and 5. Even though the normalized velocity profiles within the bare bank $(\varphi=0)$ and at the vicinity with the main channel appear to follow a logarithmic shape, this is not the case as the vegetation density increases, where they obtain a less standard shape. This is due to the local hydrodynamic sheltering past vegetation elements, further to the "blockage" effect due the whole arrangement. For example, the addition of rigid elements for the linear arrangement of $\lambda=0.06 \mathrm{~m}^{-1}$ produced a rather local (but measurable) effect (reduction of $\sim 20 \%$ of the local time-averaged flow velocities) of velocity deficit past the rods ( $w$ hen compared to $\lambda=0$ e.g., see Fig. 5a, for $y=1.010 \mathrm{~m}$ ). This local sheltering effect or "hydrodynamic shadow" downstream the individual simulated vegetation elements is very distinct. $\bar{u}$ at the riverbank region $(y=1.010 \mathrm{~m}$ to $1.250 \mathrm{~m})$ progressively decreases with increasing riverbank vegetation densities. However, at this location near the outer edge of the riverbank (e.g., $y=1.010 \mathrm{~m}$ to $1.250 \mathrm{~m}$ ) this effect is smaller for low vegetation densities (e.g., $\sim 5-10 \%$ for $\lambda=0.06-0.23 \mathrm{~m}^{-1}$ as opposed to $>50 \%$ for the higher vegetation densities $\lambda>0.47 \mathrm{~m}^{-1}$ ). For high vegetation cases $\left(\lambda=0.47\right.$ to $\left.1.88 \mathrm{~m}^{-1}\right), \bar{u}$ nearly remained almost invariant across the flow depth. The most pronounced case of local hydrodynamic shadowing is seen for 
the highest density assessed here where some negative velocities are observed at the region $y>1.090 \mathrm{~m}$. This might be representing a local back flow effect generated by the nearest upstream vegetation element, which can be relatively close to the measuring location (as small as $14 \mathrm{~mm}$ for the denser stem arrangement, configuration 6-see Fig. 3). With the increase of bank vegetation density, the slow velocity region expands in size while its magnitude is further reduced; from $\lambda=0.47$ to $1.88 \mathrm{~m}^{-1}$, the normalized flow velocity reduced $50 \%$ to more than $90 \%$ comparing to its for $\lambda=0$ to $0.23 \mathrm{~m}^{-1}$.

Careful observation of the velocity profile results suggests that near the vegetated riverbank (for $y=895$, and $945 \mathrm{~mm}$ ), the maximum mean streamwise velocity is found at a lower flow depth, compared to the other cases. The velocity-dip phenomenon occurs for straight open channel flows at the region near the walls [34-37] and diminishes closer to the main channel centreline but can be prevalent across the cross-section for relatively shallow flows (when the channel width to flow depth ratio is less than 10 and even stronger, if less than 5, see [38-40]. Here, considering the main channel's width, the aforementioned ratio becomes $W_{m} / h=1.0 / 0.125=8(<10)$, which explains why a pronounced velocity-dip phenomenon is not seen at the velocity profiles of the main channel region. As the vegetation density in the riverbank increases from $\lambda=0$ to $0.47 \mathrm{~m}^{-1}$, this will be equivalent to an increased wall roughness at the vicinity of the riverbank region, generating enhanced secondary currents, which results in the greater velocity-dip seen in Fig. 4 , for $\lambda=0.47 \mathrm{~m}^{-1}$. However, it is observed that this phenomenon does not intensify for further increasing vegetation densities $\left(\lambda>0.47 \mathrm{~m}^{-1}\right)$, possibly because the formation of secondary currents responsible for momentum exchange between the main channel and the riverbank is disrupted for denser riverbank vegetation arrangements.

Overall, these results demonstrate that the mean flow is faster at the main channel and slower at the riverbank. The increase of stem density leads to an alteration of the flow field hydrodynamics via a redistribution of the flow velocities across the channel, rather than having a demonstrable effect on the mean flow depth, which is seen to remain constant (within about $2 \%$ error). These results are also qualitatively in agreement with the work of Blanckaert et al. [41] proposing that an increase of the solid boundary roughness at the riverbank (here the increased stem density represents an increase in the equivalent roughness at the riverbank), leads to a slowing of the flow at that region.

\subsection{Bed shear stresses $(\tau)$}

As the velocity at the main channel increases with denser riverbank vegetation, the velocity gradient also becomes steeper, potentially leading to increased near bed shear stresses. At the main channel all streamwise velocity profiles follow the Law of the Wall for flow over a completely hydraulically roughened surface, which can be expressed as follows [42]:

$$
\bar{u}=A U_{f} \ln \left(\frac{30\left(z^{\prime}-z_{1}\right)}{k_{s}}\right)
$$

where $A$ is a constant $(A=2.5), U_{f}$ is the friction velocity, $z^{\prime}-z_{1}$ is the distance between the measurement location and the theoretical wall, $k_{s}$ is Nikuradse's equivalent sand grain roughness [43]. Linear regression is implemented to fit the experimental measurements of mean flow velocity to $\ln (z$ ) (only using the points within the logarithmic region of the flow profile). Bed shear stresses are then estimated by: $\tau=\rho U_{f}^{2}$. However, and similar to past research [11], using the above method for estimating shear stresses at the riverbank cannot 
be expected to offer reliable estimates, thus the focus of the discussion below is on estimates of mean bed shear stresses at the main channel.

The estimated mean bed shear stresses $(\tau)$ at the main channel (taking the average of the estimated values at locations $y=0.225 \mathrm{~m}$ and $0.445 \mathrm{~m}$, to represent the bed shear at the main channel), for a range of vegetation densities $(\varphi)$, are plotted in Fig. 6. Even though the estimation of bed shear stresses involves some uncertainty (the error bars showcase the variability of the shear stress estimates for the range of vegetation densities represented by the plotted mean), these results demonstrate a gradual overall increase of the near bed shear stresses, with increasing riverbank vegetation densities. For example, $\tau_{\mathrm{log}}$ ranges from $0.021 \mathrm{~Pa}$ for the no vegetation case to about $0.025 \mathrm{~Pa}, 0.028 \mathrm{~Pa}$ and $0.031 \mathrm{~Pa}$ for the low $(\varphi=0.06-0.08 \%)$, medium $(\varphi=0.17-0.28 \%)$ and high $(\varphi=0.55-0.99 \%)$ range of densities, an increase of approximately 20,33 and 50\%, respectively. The above results demonstrate that even though the bulk flow velocity and the mean flow depth remains practically the same for all experiments, the flow dynamics as assessed from the streamwise velocity profiles and boundary shear stresses, are the notably changing with vegetation density, due to the flow redistribution across the cross-section.

\subsection{Hydraulic roughness $\left(k_{s}\right)$}

Nikuradse's equivalent sand grain roughness $\left(k_{s}\right)$ can be computed using Eq. 3. Similarly, there exist past studies reporting hydraulic roughness derived from field data for streams with vegetated streambanks during growing and non-growing seasons [44]. Even though such studies are valuable to practitioners, the hydraulic roughness is only linked to qualitative indices of sparse to dense vegetation. Figure 7 shows the estimated roughness values, $k_{s}$, for a range of vegetation densities, generally demonstrating a slightly increasing trend.

For example, the mean computed $k_{s}$ values show an increase of up to about $35 \%$ comparing the cases of high vegetation density to the case of the bare bank. The average value of $k_{s}$, increases from $0.014 \mathrm{~m}$ to $0.021 \mathrm{~m}$, from low to high vegetation densities, which is about 7 to 10.5 times the characteristic grain size of the bed surface $\left(D_{50}\right)$. The range

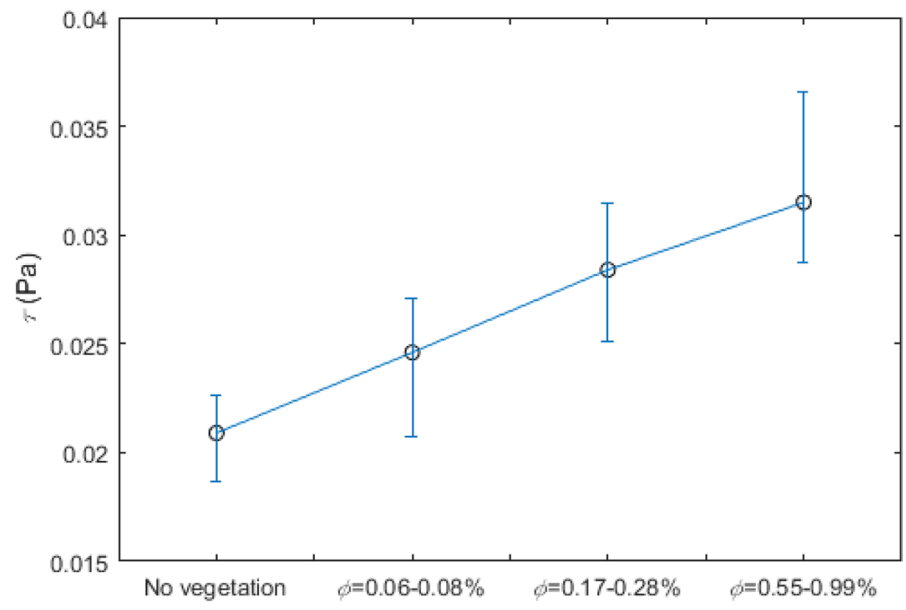

Fig. 6 Representative bed shear stresses at the main channel $(\tau \log )$, for various ranges of vegetation densities 


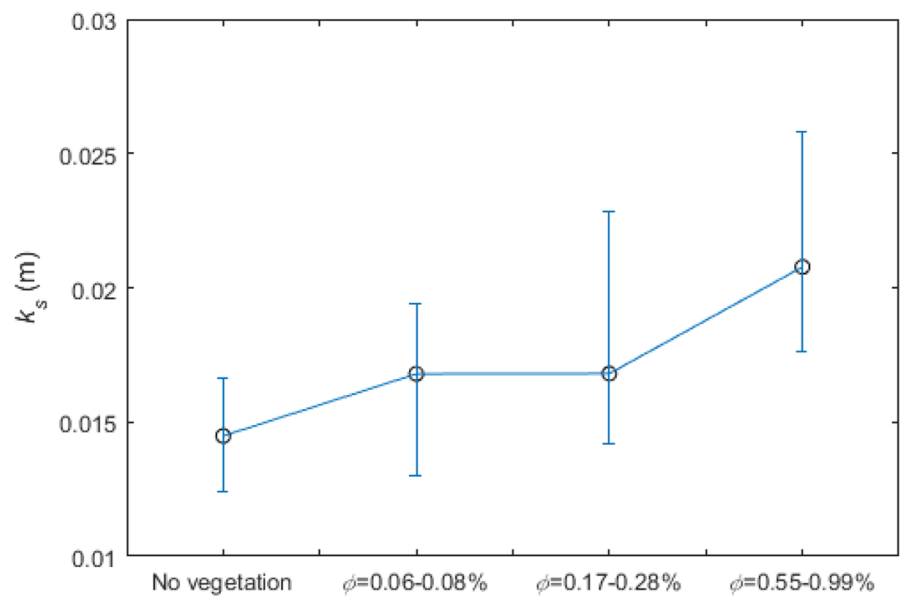

Fig. 7 Estimated values of Nikuradse's equivalent sand grain roughness $\left(k_{s}\right)($, for various ranges of vegetation densities

of computed values is also in good agreement with values of $k_{s}$ reported in the literature (e.g. Cheng [45] reports values ranging from 5 to 12.9 times the median diameter of bed material, which is consistent to the current experimental findings). In accordance to [44, 46] the results in Fig. 7 suggest that streambank vegetation can contribute to the hydraulic roughness, particularly for channels that are relatively free of other obstacles to the flow, thus leading to a redistribution of the flow velocities (acceleration at the main channel and retardation at the riverbank with increased stem density), as assessed in Figs. 4 and 5.

\section{Discussion}

\subsection{Bulk velocity and flow conveyance}

The above analysis of time averaged velocity profiles demonstrates that a clear trend exists: streamwise flow velocities are consistently lower across the riverbank with the increase of riparian vegetation, while the reverse situation holds at the main channel. This implies that for the same flow rate, the main channel/riverbank has greater/smaller conveyance (a greater/smaller percentage of the flow passes through the main channel/riverbank) respectively. Of interest is to further discuss such effects by studying the mean flow velocity across the main channel and quantify its percentage (\%) change, estimated with a number of different ways, as elaborated further below.

First, a reasonably good estimate of the spatiotemporally averaged velocity can be obtained by using the area weighted point streamwise velocity measurements across sections of the channel, considering the constant flow depth across the width of the asymmetrical cross-section $(h=0.125 \mathrm{~m}$, as measured with rulers fixed at the side of the flume wall and digital depth measurement gauges along the width of the cross-section of the channel, for the constant flow rate used in the experiments herein). Figure 8 shows the ratios of the bulk flow velocity for a certain vegetation density to that of the bare bank, $\frac{\bar{u}}{\overline{u_{0}}}$, estimated considering velocimetry measurements from $y=0.245$ to $0.645 \mathrm{~m}$ (shown with triangles) and $\mathrm{y}=0.245 \mathrm{~m}$ to $1.000 \mathrm{~m}$ (shown with crosses). Another estimate of the bulk flow 


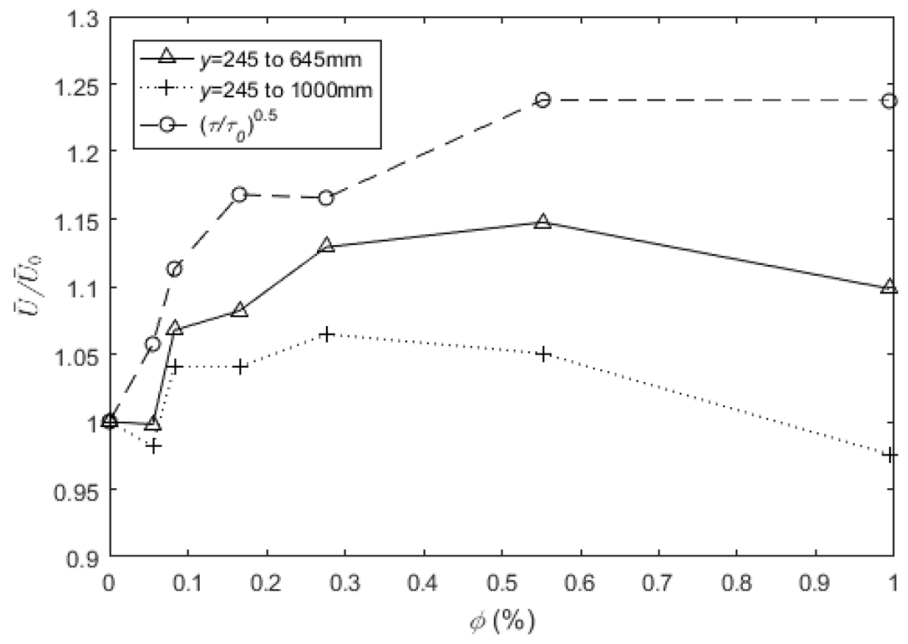

Fig. 8 Ratios of the bulk velocities through the main channel $\left(\frac{\bar{u}}{\overline{u_{0}}}\right)$ for different vegetation densities $(\varphi)$ to that of the bare bank $(\varphi=0) \frac{\bar{u}}{\overline{u_{0}}}$, estimated considering: a velocimetry measurements from $y=0.245 \mathrm{~m}$ to $0.645 \mathrm{~m}$ (shown with open triangle symbols), b velocimetry measurements from $\mathrm{y}=0.245 \mathrm{~m}$ to $1.000 \mathrm{~m}$ (shown with crosses), and cestimates of bed shear stresses from $y=0.245 \mathrm{~m}$ to $0.645 \mathrm{~m}$

velocity can be derived from the estimated mean bed shear stresses, considering that they are linearly related to the square of the mean velocity [47]. Then the ratio of bulk flow velocities $\frac{\bar{u}}{\overline{u_{0}}}$ can be derived from the calculation of the square root of the ratio of mean bed shear stresses for the respective cases $\left(\bar{U} / \overline{U_{0}}=\sqrt{\bar{\tau} / \overline{\tau_{0}}}\right) \overline{\mathrm{U}} / \overline{\mathrm{U}_{0}}=\sqrt{\overline{\bar{\tau}} / \bar{\tau}_{0}}$. The above ratio $\left(\frac{\bar{u}}{\overline{u_{0}}}\right)$ based on bed shear stresses, $\tau$, from $y=0.245 \mathrm{~m}$ to $0.645 \mathrm{~m}$, is plotted in Fig. 8 , with the open circles. This method, according to Wilcock [47], can return reasonable estimates under the assumption of relatively simple cross-sectional geometry, where the flow field structure follows a regular structure, which holds true for the region from $y=0.245$ to $0.645 \mathrm{~m}$. It needs be noted that the friction factor relating the above ratios may be changing with vegetation density, which may imply that increased estimation uncertainties exist, for the higher stem densities (e.g., see Fig. 8 for $\varphi>0.28 \%$,).

It can be observed that for all values of vegetation density (here parameterized by $\varphi$ ) the velocity ratios follow the same trend overall. The main finding is that the bulk velocity $(\bar{U})$ at the main channel $(y=0.225$ to $0.945 \mathrm{~m})$ increases up to $15-20 \%$, from $\varphi=0.06 \%$ to $0.44 \%$ compared to the bare bank case. With increasing riverbank vegetation, the shear layer and flow "blockage effect" extends well beyond the riverbank and this is the reason why the bulk velocity ratio $\frac{\bar{U}}{\overline{U_{0}}}$ calculated from $y=0.245$ to $0.645 \mathrm{~m}$ (shown with triangles) and $\mathrm{y}=0.245$ to $1.000 \mathrm{~m}$ (shown with crosses) is seen to reduce for $\varphi=0.99 \%$ and from $\varphi$ $=0.55 \%$, respectively. The estimate based on the ratio of shear stresses $\left(\tau / \tau_{0}\right)$ is systematically higher than the other estimates, even though within a notably small error of up to $10 \%$ for $\varphi=0.44 \%$. Despite the uncertainties inherited from the methods of estimation the results are relatively consistent for the low densities, up to $\varphi=0.28 \%$, for all methods of estimation, showing an increase of the bulk flow velocity through the main channel. The main reason the estimates based on spatial integration of the velocity measurements are 
showing a deviation from the above trend is because for higher stem densities the shearing layer is pushed towards the main channel, resulting in lower velocities for the region near the riverbank (e.g., see Fig. 8 for $\varphi>0.28 \%$,).

The bulk flow velocity representative of the whole channel is also calculated across the channel's cross-section using all available velocimetry measurements (see cross symbols, in Fig. 9). A slight decrease for this estimate is observed as vegetation density increases, which corresponds to the overall slowing of the flow due to increasing flow resistance. This decrease is almost linearly dependent on the riverbank vegetation density $\left(R^{2}=0.99\right.$ for $\varphi>0.083$, see Fig. 9):

$$
\frac{\bar{U}}{\overline{U_{0}}}=1-0.143 \varphi
$$

This equation (Eq. 4) may be of interest to practitioners and researchers alike, who want to express in an accessible manner the effect of riparian vegetation density on the mean flow velocity of the main channel, relevant to the case with bare banks. These results can be generalised, under the condition of geometric similarity, for flows through channels having the same ratios of $W_{v} / W_{m}$ and $h / W_{m}$.

Similarly, Fig. 9 shows that the bulk velocity at the riverbank region decreases from the case of no vegetation to that of dense vegetation configurations (e.g., $\varphi=0.55-0.99 \%)$. It can be seen that the ratio of bulk velocities at the riverbank, is most influenced, exhibiting five times decrease, from $\varphi=0$ to $0.99 \%$, while the corresponding drop across the whole channel is about $17 \%$, with an about $15-20 \%$ increase for the main channel, which corresponds to a change in the equivalent roughness similar to [41], for increasing boundary roughness. The decrease with the riverbank vegetation density $(\varphi)$, can be shown to follow

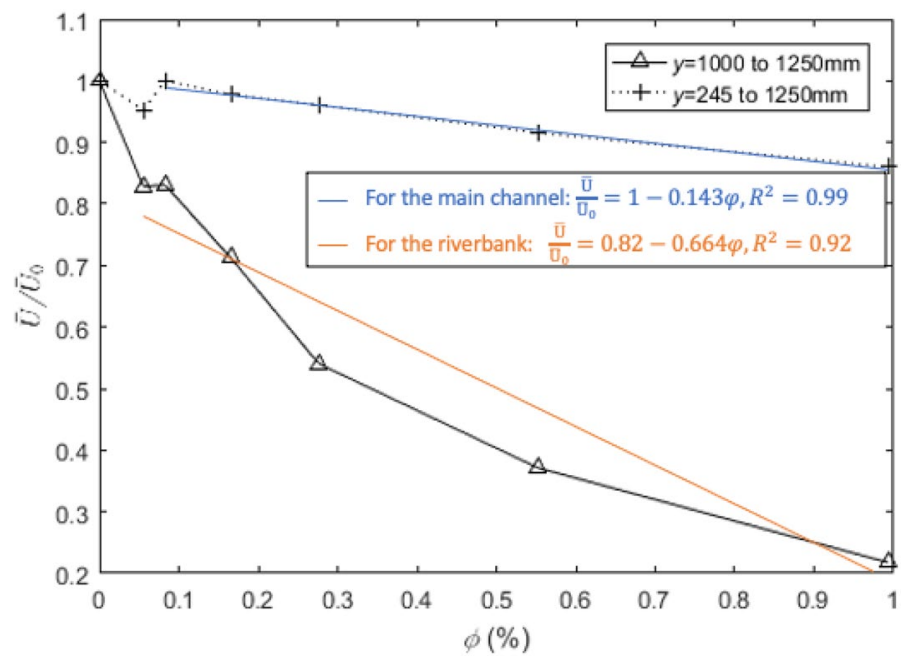

Fig. 9 Ratios of the bulk velocities $\left(\frac{\bar{u}}{\bar{u}_{0}}\right)$ for certain vegetation densities $(\varphi)$ to that of the bare bank $(\varphi=0)$ estimated using velocimetry data: a across the whole channel (from $y=0.245 \mathrm{~m}$ to $1.250 \mathrm{~m}$, shown with cross symbols), and $\mathbf{b}$ across the riverbank (from $y=1.000 \mathrm{~m}$ to $1.250 \mathrm{~m}$, shown with open triangle symbols) 
a quadratic decrease with $\varphi$, yet here a simple but practical linear fit can be obtained to a good approximation $\left(R^{2}=0.92\right.$ for $\varphi>0.056$, see Fig. 9):

$$
\frac{\bar{U}}{\overline{U_{0}}}=0.82-0.664 \varphi
$$

It is of good interest to note the effect of the arrangement (linear and rectilinear arrangements, for a given relative increase in vegetation density), to the main channel flow velocities and bed shear stresses. Specifically, it is seen that the transition from a linear to a rectilinear arrangement, relatively to the flow direction, will have a relatively greater effect in increasing the amount of flow through the main channel $\left(\frac{\bar{U}}{\overline{U_{0}}}\right)$, for the low vegetation densities (eg $\varphi=0-0.6 \%$ ). For example, Fig. 8 shows that there is almost no change in $\frac{\bar{U}}{\bar{U}_{0}}$ for the cases of vegetation density increasing from bare bank to the first configuration (linear), configuration 2 (rectilinear) to configuration 3 (linear), as well as configuration 4 (rectilinear) to configuration 5 (linear). The opposite holds for increasing vegetation density, while changing from linear to rectilinear arrangements of the individual vegetation elements (rods). For example, Fig. 8 shows an increase in $\frac{\bar{U}}{\bar{U}_{0}}$ for a change from configurations 1 (linear) to 2 (rectilinear) and 3 (linear) to 4 (rectilinear). The observed trend that the mean flow velocity at the main channel, is increasing, when transitioning from a linear to a rectilinear arrangement, is consistent with the fact that new elements are seen by the flow through the riverbank. This is so even if the relative change in density is greater (in terms of $\varphi$, Fig. 8), when transitioning from a rectilinear to a linear arrangement. In the former case the effective blockage area to the flow through the riverbank is increasing, while in the latter case, this is not happening (as the vegetation elements added to form the linear arrangement, fall within the hydrodynamic shadow of the elements forming the rectilinear arrangement). This observation is consistent with other experimental findings from the literature. For example, [48] found that staggered (or rectilinear) vegetation arrangements offer a greater amount of resistance (hydrodynamic drag) compared to the linear vegetation configurations of similar density. Considering that the mean flow velocity deficit relates directly to the drag force exerted by the vegetation patch, shows that our findings are in agreement with their observations.

However, there is a reversal of the effect for higher densities (e.g., $\varphi>0.6 \%$ ). Specifically, there is a reduction of the flow velocity from arrangement 5 (linear) to 6 (rectilinear), apparently reflecting the slowing of the flow throughout the channel (also explained, by the substantially increased resistance at the riverbank).

\subsection{Implications for the stability of bed surface at the main channel}

Shields shear stresses, $\tau_{*}$, can be calculated as:

$$
\tau_{*}=\frac{U_{f}^{2}}{g\left(S_{s}-1\right) k}
$$

where $S_{\mathrm{s}}$ is the specific gravity of sediment grains, $g$ is the gravitational acceleration and $\mathrm{k}=D_{50}$ considering the bed surface is stable. Shields shear stresses at various locations of the main channel $(y=0.245$ to $0.645 \mathrm{~m})$ can be computed (Table 2). Overall, the highest 
Table 2 Shields bed shear stresses, for specific transverse locations $y$ and for various riverbank vegetation densities $(\varphi=0-0.99 \%)$

\begin{tabular}{llllllll}
\hline$\tau_{*} \times 10^{-3}$ & $\varphi=0$ & $\varphi=0.06 \%$ & $\varphi=0.08 \%$ & $\varphi=0.17 \%$ & $\varphi=0.28 \%$ & $\varphi=0.55 \%$ & $\varphi=0.99 \%$ \\
\hline$y=0.245 \mathrm{~m}$ & 0.95 & 0.91 & 1.17 & 1.15 & 1.11 & 1.36 & 1.27 \\
$y=0.445 \mathrm{~m}$ & 0.83 & 1.04 & 1.06 & 1.24 & 1.30 & 1.48 & 1.62 \\
$y=0.645 \mathrm{~m}$ & 1.00 & 1.14 & 1.20 & 1.39 & 1.36 & 1.41 & 1.35 \\
\hline
\end{tabular}

bed shear stresses are observed at the centerline of the main channel, increasing with riverbank vegetation density.

It is seen in Table 2 that bed shear stresses at the main channel are generally increasing with vegetation density, which is overall satisfying considering the large uncertainties (of up to an order of magnitude when comparing bed shear stresses [3]). For example, an increase of about $90 \%$ can be seen when the maximum values of bed shear stress for the case of no vegetation and $\varphi=0.99 \%$ are compared. It is also interesting to compare the increase of bed shear stresses at fixed locations as vegetation density increases. Shear stresses at the same location (e.g., for $y=0.445 \mathrm{~m}$ ) are observed to double when the cases of no vegetation and $\varphi=0.99 \%$ are compared (Table 2 ).

Comparing each transverse location (y) greater $\tau_{*}$ values are observed at $y=0.645 \mathrm{~m}$ for $\varphi=0.00-0.28 \%$ and at $y=0.445 \mathrm{~m}$ for $\varphi=0.55-0.99 \%$. This shows a relative shifting of the highest shear region towards the main channel with the increase of riverbank vegetation, which is consistent with the expansion of the shear layer towards the main channel, as the flow "blockage" effect at the riverbank increases.

Even though, in the present experiments the channel bed surface is designed to be stable, as is also confirmed given that the range of Shields shear stresses range from 0.0008 to 0.0015 which is well below the range of critical Shields values for entrainment (0.003-0.006), the aforementioned results (Table 2) showcase an increased probability for bed material transport at the main channel, as vegetation density increases at the sloping riverbank. Similarly, Chen and Chan [49] linked the erosional capacity of the flow to the increased bed shear stresses around vegetation elements. Such processes would lead to deepening of the main channel, while the banks may be further reinforced via the root system preventing their failure [50-55]. Observations of increasing depth and decreasing width of the main channel with riparian vegetation are replicated in physical models of open channel flows by Ikeda and Izumi [56], and field observation by Charlton et al. [57] and Andrews [58].

The current findings allow for a better assessment of how the flow dynamics are affected by the density and arrangement of vegetation, rendering it useful for enabling more robust designs of river restoration efforts as well as assessing the effectiveness of re-vegetation activities, which is much needed [1]. This can be achieved via linking any changes in riverbank stem density to quantifiable effects on flow dynamics (Eq. 4), and the potential for riverbed destabilization.

However, future research should further aim to assess the stability of the vegetated riverbank, in addition to the main channel. As recent studies have shown [3, 59] bed shear stresses may not be the most robust criterion for assessing the stability of vegetated riverbanks. Further analysis using novel event-based criteria for sediment transport through or past vegetation, appropriately accounting for the size and energy content of turbulent flow structures [60-62, 64] or turbulent kinetic energy [59], may be useful to pursue further 
in future studies. The importance of utilizing such criteria is perhaps even more apparent when the variation of the mean bed shear stresses is relatively small (as is the case for the experiments reported herein) and the uncertainties inherent in its calculation (also highly depending on the method of estimation) can be quite considerable [3, 63, 64].

\section{Conclusions}

A series of flume experiments are conducted to assess and quantify the effect of increasing riverbank vegetation densities on flow dynamics, both at the riverbank and at the main channel. Streamwise flow velocity at the main channel/riverbank may increase/ decrease, with increasing riverbank vegetation density respectively, as assessed with velocity profile measurements.

It is found that with increasing vegetation density, flow velocity increases at the main channel, while reducing at the riverbank and these effects are quantified. These flow measurements are analyzed to derive estimated values for the time-averaged bed shear stresses at the main channel, which enable further discussing implications for the stability of bed surface material. Assessing the flow dynamics at the centerline of the main channel $(y=0.445 \mathrm{~m})$ an increase of about $18 \%$ can be observed mid-depth of the flow $(z / h=0.5)$, from $\varphi=0.12 \%$ or $\lambda=0.12 \mathrm{~m}^{-1}$ to $\varphi=0.99 \%$ or $\lambda=1.88 \mathrm{~m}^{-1}$.

Bulk flow velocity at the riverbank region, progressively decreases from the case of no vegetation to that of dense vegetation configurations, exhibiting a drop of up to $17 \%$ across the whole channel. As vegetation density increases from $\varphi=0$ to $0.99 \%$, the mean flow velocity at the riverbank can decrease five-fold (leading to the flow "blockage" effect), while the corresponding, increase for the main channel is about 15-20\%.

Herein, the increase of riverbank vegetation, from $\varphi=0$ to $0.99 \%$, is seen to lead to an approximate doubling of mean bed shear stresses at the centerline of the main channel as well as an increase of the bed roughness as is parameterized by Nikuradse's equivalent sand grain roughness $\left(\mathrm{k}_{s}\right)$.

The role of the riverbank vegetation on the mean flow velocity at the main channel is also assessed. It is found that the mean flow velocity at the main channel is greater for the rectilinear configurations, when comparing linear and rectilinear arrangements of about the same vegetation density. Arrangements with twice the density (in terms of $\lambda$ ), but the same frontal area exposure to the flow will have about the same impact on modifying the mean flow at the main channel, (effect of the hydrodynamic sheltering). This effect reduces for denser vegetation patches $(\varphi>0.6 \%)$, reflecting the greater role of increasing equivalent flow resistance at higher densities. Thus, vegetation arrangement can be of equal importance as the density of vegetation, in modifying the mean flow velocity, for low riparian densities.

As the assessment of the stability of the main channel and riverbank is critical in quantifying, modeling and predicting geomorphic processes across the channel, it will be important to search for robust stability criteria, in addition to mean shear stresses, such as turbulent kinetic energy [46] and event-based criteria (impulse [47, 48] and energy [49]).

Acknowledgements The authors would like to acknowledge the support of The Royal Society (Research Grant RG2015 R1 68793/1) and The Royal Society of Edinburg (Scottish Crucible Award). 
Open Access This article is licensed under a Creative Commons Attribution 4.0 International License, which permits use, sharing, adaptation, distribution and reproduction in any medium or format, as long as you give appropriate credit to the original author(s) and the source, provide a link to the Creative Commons licence, and indicate if changes were made. The images or other third party material in this article are included in the article's Creative Commons licence, unless indicated otherwise in a credit line to the material. If material is not included in the article's Creative Commons licence and your intended use is not permitted by statutory regulation or exceeds the permitted use, you will need to obtain permission directly from the copyright holder. To view a copy of this licence, visit http://creativecommons.org/licenses/by/4.0/.

\section{References}

1. Bernhard ES et al (2005) Synthesizing U.S. River Restoration Efforts. Science 308:636-637. https://doi.org/10.1126/science.1109769

2. Czarnomski NM (2010) Influence of vegetation on streambank hydraulics, PhD Thesis. Oregon State University, Oregon, United States of America

3. Hopkinson LC, Wynn-Thompson TM (2016) Comparison of direct and indirect boundary shear stress measurements along vegetated streambanks. River Res Appl 32(8):1755-1764. https://doi. org/10.1002/rra.3010

4. Yang K, Cao S, Knight DW (2007) Flow patterns in compound channels with vegetated floodplains. J Hydraul Eng ASCE 133:148-159. https://doi.org/10.1061//ASCE/0733-9429/2007/133:2/ 148

5. Nepf HM (1999) Drag, turbulence, and diffusion in flow through emergent vegetation. Water Resour Res 35:479-489. https://doi.org/10.1029/1998wr900069

6. Tsujimoto T, Shimizu Y, Kitamura T, Okada T (1992) Turbulent open-channel flow over bed convered by rigid vegetation. J Hydrosc Hydraul Eng 10(2):13-25

7. Wilson CAME, Stoesser T, Bates PD, Pinzen AB (2003) Open channel flow through different forms of submerged flexible vegetation. J Hydraul Eng ASCE 129:847-853. https://doi.org/10.1061//ASCE/ 0733-9429/2003/129:11/847

8. Liu D, Diplas P, Hodges CC, Fairbanks JD (2010) Hydrodynamics of flow through double layer rigid vegetation. Geomorphology 116:286-296. https://doi.org/10.1016/j.geomorph.2009.11.024

9. Zong L, Nepf H (2010) Flow and deposition in and around a finite patch of vegetation. Geomorphology 116:363-372. https://doi.org/10.1016/j.geomorph.2009.11.020

10. Neary VS, Constantinescu SG, Bennett SJ, Diplas P (2012) Effects of vegetation on turbulence, sediment transport, and stream morphology. J Hydraul Eng ASCE 138:765-776. https://doi.org/10.1061/ (asce)hy.1943-7900.0000168

11. Hopkinson L, Wynn T (2009) Vegetation impacts on near bank flow. Ecohydrology 2:404-418. https:// doi.org/10.1002/eco.87

12. Czarnomski NM, Tullos DD, Thomas RE, Simon A (2012) Effects of vegetation canopy density and bank angle on near-bank patterns of turbulence and reynolds stresses. J Hydraul Eng ASCE 138:974978. https://doi.org/10.1061/(asce)hy.1943-7900.0000628

13. Kitsikoudis V, Yagci O, Kirca VSO, Kellecioglu D (2016) Experimental investigation of channel flow through idealized isolated tree-like vegetation. Env Fluid Mech 16(6):1283-1308

14. Yagci O, Celik F, Kitsikoudis V, Kirca VSO, Hodoglu C, Valyrakis M, Duran Z, Kaya S (2016) Scour patterns around individual vegetation elements. Adv Water Resour 97:251-265. https://doi.org/10. 1016/j.advwatres.2016.10.002

15. Yager EM, Schmeeckle MW (2013) The influence of vegetation on turbulence and bed load transport. J Geophys Res 118:1585-1601. https://doi.org/10.1002/jgrf.20085

16. Rominger JT, Lightbody AF, Nepf HM (2010) Effects of added vegetation on sand bar stability and stream hydrodynamics. J Hydraul Eng 136:994-1002. https://doi.org/10.1061//ASCE/HY.1943-7900. 0000215

17. Nepf HM, Vivoni ER (2000) Flow structure in depth-limited, vegetated flow. J Geophys Res 105(28):549-557

18. Liu D, Diplas P, Fairbanks JD, Hodges CC (2008) An experimental study of flow through rigid vegetation. J Geophys Res. https://doi.org/10.1029/2008jf001042

19. Kang H, Choi SU (2006) Turbulence modeling of compound open-channel flows with and without vegetation on the floodplain using the Reynolds stress model. Adv Water Resour 29:1650-1664. https://doi.org/10.1016/j.advwatres.2005.12.004 
20. Huai WX, Zeng YH, Xu ZG, Yang ZH (2009) Three-layer model for vertical velocity distribution in open channel flow with submerged rigid vegetation. Adv Water Resour 32:487-492. https://doi.org/10. 1016/j.advwatres.2008.11.014

21. Jahra F, Kawahara Y, Hasegawa F, Yamamoto H (2011) Flow-vegetation interaction in a compound open channel with emergent vegetation. Intern J River Basin Manag 9:247-256. https://doi.org/10. 1080/15715124.2011.642379

22. Nepf H, Rominger J, Zong L (2013) Coherent FLOW STRUCTURES IN VEGETATED CHannels. In: Venditti JG, Best JL, Church M, Hardy RJ (eds) Coherent flow structures at Earth's surface, 1st edn. Wiley, Hoboken

23. Chen Z, Ortiz A, Zong L, Nepf H (2012) The wake structure behind a porous obstruction and its implications for deposition near a finite patch of emergent vegetation. Water Resour Res 48:W09517. https://doi.org/10.1029/2012wr012224

24. Schmeeckle MW (2014) Numerical simulation of turbulence and sediment transport of medium sand. J Geophys Res Earth Surf 119:1240-1262. https://doi.org/10.1002/2013JF002911

25. Sumer BM, Chua LHC, Cheng NS, Fredsøe J (2003) Influence of turbulence on bed load sediment transport. J Hydraul Eng ASCE 129:585-596. https://doi.org/10.1061//ASCE/0733-9429/2003/129:8/ 585

26. Liu D, Valyrakis M, Williams R (2017) Flow hydrodynamics across an open channel flow with a riparian zone: implications for riverbank stability. Water 9(9):720. https://doi.org/10.3390/w9090720

27. Lien K, Monty JP, Chong MS and Ooi A (2004) The entrance length for fully developed turbulent channel flow, 15th Australasian fluid mechanics Conference Sydney, Australia

28. Vandenbruwaene $\mathrm{W}$ et al (2011) Flow interaction with dynamic vegetation patches: implications for biogeomorphic evolution of a tidal landscape. J Geophys Res 116:F01008. https://doi.org/10.1029/ 2010JF001788

29. Struve J, Falconer RA, Wu Y (2003) Influence of model mangrove trees on the hydrodynamics in a flume. Estuar Coast Shelf Sci 58(1):163-171. https://doi.org/10.1016/S0272-7714(03)00072-6

30. Leonard L, Wren PA (2002) Flow dynamics and sedimentation in Spartina Alterniflora and Phragmites Australis marshes of the Chesapeake Bay. Wetlands 22(2):415-424

31. Lightbody A (2006) Prediction of velocity profiles and longitudinal dispersion in emergent salt marsh vegetation. Limnol Oceanogr 51(1):218-228

32. Widdows J, Pope N, Brinsley M (2008) Effect of Spartina anglica stems on near-bed hydrodynamics, sediment erodability and morphological changes on an intertidal mudflat. Mar Ecol Prog Ser 362:45-57

33. Goring DG, Nikora V (2002) Despiking acoustic doppler velocimeter data. J Hydraul Eng ASCE 128:117-126. https://doi.org/10.1061//ASCE/0733-9429/2002/128:1/117

34. Sarma KVN, Lakshminarayana P, Lakshmana Rao NS (1983) Velocity distribution in smooth rectangular open channel. J Hydraul Eng ASCE 109:270-289

35. Yang SQ, Tan SK, Lim SY (2004) Velocity distribution and dip phenomenon in smooth uniform open channel flow. J Hydraul Eng ASCE 130:1179-1186

36. Yan J, Tang H, Xiao Y, Li K, Tian Z (2011) Experimental study on influence of boundary on location of maximum velocity in open channel flows. Water Sci Eng 4:185-191

37. Bonakdari H, Larrarte F, Lassabatere L, Joannis C (2008) Turbulent velocity profile in fully-developed open channel flows. Environ Fluid Mech 8:1-17

38. Nezu I, Rodi W (1986) Open channel flow measurements with a laser Doppler anemometer. J Hydraul Eng ASCE 112:335-355

39. Greco M, Moramarco T (2016) Influence of bed roughness and cross section geometry on medium and maximum velocity ratio in open-channel flow. J Hydraul Eng ASCE 142:06015015

40. Moramarco T, Termini D (2015) Entropic approach to estimate the mean flow velocity:experimental investigation in laboratory flumes. Environ Fluid Mech 15:1163-1179

41. Blanckaert K, Duarte A, Schleiss AJ (2010) Influence of shallowness, bank inclination and bank roughness on the variability of flow patterns and boundary shear stress due to secondary currents in straight open-channels. Adv Water Resour 33(9):1062-1074. rrr

42. Nezu I, Nakagawa H (1993) Turbulence in open-channel flows. Balkema, Rotterdam

43. Guo J, Julien PY (2005) Shear stress in smooth rectangular open-channel flows. J. Hydraul. Eng. ASCE. 131:30-37. https://doi.org/10.1061/(ASCE)0733-9429(2005)131:1(30)

44. Coon WF (1998) Estimation of roughness coefficients for natural stream channels with vegetated banks' Water Supply Paper. http://pubs.er.usgs.gov/publication/wsp2441 ISBN:060788701X

45. Cheng NS (2016) Representative grain size and equivalent roughness height of a sediment bed. J Hydraul Eng ASCE. 142(1):06015016. https://doi.org/10.1061/(ASCE)HY.1943-7900.0001069 
46. Fenzl RN, Davis JR (1964) Hydraulic resistance relationships for surface flows in vegetated channels. Trans ASCE 7(1):46-55

47. Wilcock PR (1996) Estimating local bed shear stress from velocity observations. Water Resour Res 32(11):3361-3366. https://doi.org/10.1029/96WR02277

48. Li RM, Shen HW (1973) Effect of tall vegetation on flow and sediment. J Hydraul Div Am Soc Civ Eng 99(HY5):793-814

49. Chen SC, Chan HC, Li YH (2012) Observations on flow and local scour around submerged flexible vegetation. Adv Water Resour 43:28-37. https://doi.org/10.1016/j.advwatres.2012.03.017

50. Hubble TCT, Docker BB, Rutherfurd ID (2010) The role of riparian trees in maintaining riverbank stability: a review of Australian experience and practice. Ecol Eng 36:291-304. https://doi.org/10.1016/j. ecoleng.2009.04.006

51. Huang HQ, Nanson GC (1997) Vegetation and channel variation; a case study of four small streams in southeastern Australia. Geomorphology 18:237-249

52. Anderson RJ, Bledsoe BP, Hession WC (2004) Width of streams and rivers in response to vegetation, bank material, and other factors. J Amer Water Res Assoc 40:1159-72

53. Millar RG, Quick MC (1993) Effects of bank stability on geometry of gravel rivers. J Hydraul Eng ASCE 119:1343-1363

54. Perona P, Camporeale C, Perucca E, Savina M, Molnar P, Burlando P, Ridolfi L (2009) Modelling river and riparian vegetation interactions and related importance for sustainable ecosystem management. Aquat Sci 71:266-278

55. Perona P, Molnar P, Savina M, Burlando P (2009) An observation-based stochastic model for sediment and vegetation dynamics in the floodplain of an alpine braided river. Water Resour Res 45:W09418

56. Ikeda S, Izumi N (1990) Width and depth of self-formed straight gravel rivers with bank vegetation. Water Resour Res 26(10):2353-2364. https://doi.org/10.1029/WR026i010p02353

57. Charlton FG, Brown FM, Benson RW (1978) The hydraulic geometry of some gravel rivers in Britain. Hydraulic Research Station, Wallingford

58. Andrews ED (1984) Bed-material entrainment and hydraulic geometry of gravel-bed rivers in Colorado. GSA Bull 95(3):371-378. https://doi.org/10.1130/0016-7606(1984)95\%3c371:BEAHGO\% 3e2.0.CO;2

59. Yang JQ, Chung H, Nepf HM (2016) The onset of sediment transport in vegetated channels predicted by turbulent kinetic energy. Geoph Res Lett. https://doi.org/10.1002/2016GL071092

60. Diplas P, Dancey CL, Celik AO, Valyrakis M, Greer K, Akar T (2008) The role of impulse on the initiation of particle movement under turbulent flow conditions. Science 322:717-720. https://doi.org/10. 1126/science. 1158954

61. Valyrakis M, Diplas P, Dancey CL, Greer K, Celik AO (2010) The role of instantaneous force magnitude and duration on particle entrainment. J Geophys Res Earth Surf 115(F2):F02006. https://doi.org/ 10.1029/2008JF001247

62. Valyrakis M, Diplas P (2013) CL Dancey (2013) Entrainment of coarse particles in turbulent flows an energy approach. J Geophys Res Earth Surf 118:42-53. https://doi.org/10.1029/2012jf002354

63. Buffington JM, Montgomery DR (1997) A systematic analysis of eight decades of incipient motion studies, with special reference to gravel-bedded rivers. Water Resour Res 33(8):1993-2029. https://doi. org/10.1029/96WR03190

64. Pähtz T, Clark AH, Valyrakis M, Durán O (2020) The physics of sediment transport initiation, cessation, and entrainment across aeolian and fluvial environments. Rev Geophys. https://doi.org/10.1029/ 2019RG000679

Publisher's Note Springer Nature remains neutral with regard to jurisdictional claims in published maps and institutional affiliations. 


\section{Authors and Affiliations}

\section{Manousos Valyrakis ${ }^{1}$ (D) Da Liu ${ }^{1} \cdot$ Umut Turker $^{2} \cdot$ Oral Yagci $^{3}$}

1 Infrastructure and Environment Research Division, School of Engineering, University of Glasgow, Glasgow G12 8LT, UK

2 Civil Engineering Department, Eastern Mediterranean University, Mersin 10, Famagusta, North Cyprus , Turkey

3 Division of Hydraulics, Civil Engineering Department, Istanbul Technical University, 34469 Maslak, Istanbul, Turkey 